Chapter 4

\title{
Application of Nanotechnology in Drug Delivery
}

\author{
Joana Silva, Alexandra R. Fernandes and \\ Pedro V. Baptista \\ Additional information is available at the end of the chapter \\ http://dx.doi.org/10.5772/58424
}

\section{Introduction}

\subsection{Nanomedicine for cancer}

Cancer is one of the leading causes of death worldwide, occupying the second place in developing countries, and showing a growing incidence over time [1]. Current cancer therapy strategies are based in surgery, radiotherapy and chemotherapy, being the chemotherapy the one that shows the greater efficiency for cancer treatment, mainly in more advanced stages [2, 3]. Despite of this great response, anticancer agents are administrated at higher amounts in order to provide a final suitable concentration to the target tissues or organs, and this procedure is repeated in each cycle of chemotherapy [4]. Introduction of new agents to cancer therapy has greatly improved patient survival but still there are several biological barriers that antagonize drug delivery to target cells and tissues, namely unfavorable blood half-life and physiologic behavior with high off-target effects and effective clearance from the human organism [2, 5, 6]. Moreover, in cancer, there is a small subset of cancer cells-cancer stem cells (CSC)-that, like normal stem cells, can self-renew, give rise to heterogeneous populations of daughter cells, and proliferate extensively $[7,8]$. Standard chemotherapy is directed against rapidly dividing cells, the bulk of non-stem cells of a tumor, and thus CSC often appear relatively refractory to those agents [7-9]. The development of side effects in normal tissues (e.g. nephrotoxicity, neurotoxicity, cardiotoxicity, etc) and multidrug resistance (MDR) mechanisms by cancer cells leads to a reduction in drug concentration at target location, a poor accumulation in the tumor with consequent reduction of efficacy that may associate to patient relapse [9-13]. To overcome these issues and still improve the efficiency of chemotherapeutic agents there is a demand for less toxic and more target specific therapies towards cancer cells, i.e. novel drugs, drug delivery systems (DDSs) and also gene delivery systems [3, 4, 14-17]. 
Nanotechnology is the manipulation of matter on an atomic, molecular, and supramolecular scale involving the design, production, characterization and application of different nanoscale materials in several key areas providing novel technological advances mainly in the field of medicine (so called Nanomedicine) [6, 18-20]. The development and optimization of drug delivery approaches based in nanoparticles concerns the early detection of cancer cells and/or specific tumor biomarkers, and the enhancement of the efficacy of the treatments applied [21]. The most important biomedical applications of nanoscale materials can be organized as shown in Figure 1.

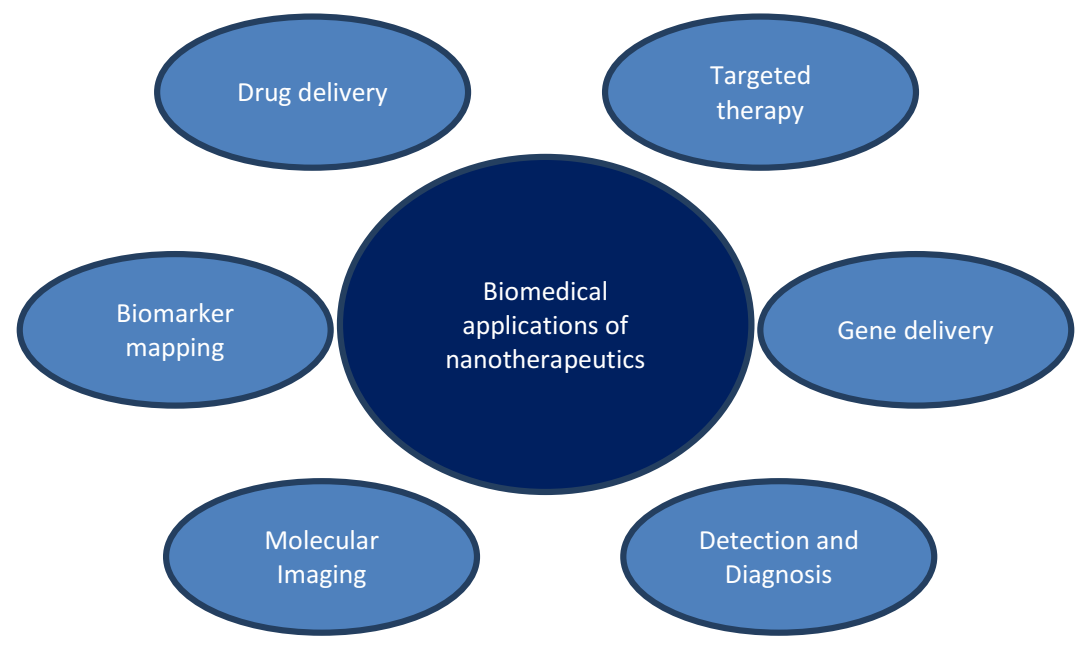

Figure 1. Biomedical application of nanotherapeutics (adapted from [6]).

These nanotherapeutics' potential in cancer relies on i) passive targeting due to the enhance of the permeability and retention (EPR) effect promoted by angiogenic vessels with defective vasculature and improper lymphatic flow surrounding the tumor [18] that can be reinforced by ii) specific targeting based on multifunctional nanomaterials that bypass the biological barriers and reach cancer cells [4]. Nanotechnology for drug vectorization provides for new and more specific drug targeting and delivery platforms that can reduce toxicity and other side effects and also maintain or improve the therapeutic index $[9,22,23]$. In fact, the development of targeting delivery systems is the ultimate goal in cancer therapy, which has been taking the lead in what concerns overcoming the MDR problem [9, 13, 24, 25].

Here, we will discuss recent applications on AuNPs as platforms for anticancer therapy, emphasizing strategies for targeted delivery for gene silencing focusing on the optimal pathways to test these therapeutics in vitro and in vivo. Also, an overview of the toxicological aspects of these materials will be provided. 


\section{Nanoparticles as delivery systems}

Nanoparticles have been developed as effective target specific strategies for cancer treatment, acting as nanocarriers and also as active agents $[4,6,5,26]$. Over the last decades, different types of nanoparticles have been developed based on various components, including carbon, silica oxides, metal oxides, nanocrystals, lipids, polymers, dendrimers, and quantum dots, together with increasing variety of newly developed materials [4, 27-34]. These nanomaterials are capable to provide a high degree of biocompatibility before and after conjugation to biomolecules for specific function so as to translate into nanomedicines and clinical practice. Nanomaterials provide for a favorable blood half-life and physiologic behavior with minimal off-target effects, effective clearance from the human organism, and minimal or no toxicity to healthy tissues in living organisms $[35,36]$.

In fact, the protection from adsorption to plasma proteins and/or degradation by circulating nucleases allows for an increased availability of effector molecule at site of interest. This is further enhanced by the considerable decrease to clearance from the organism that conjugation to nanoparticles confers. The modulation of pharmacokinetic and pharmacodynamics parameter constitutes a key factor when modifying the mode of administration (and vehicle and route of administration associated) that is usually neglected when compared to the ability of therapeutic nanoconjugates to offer the possibility of enhanced targeting (active and/or passive) and cell uptake. When considering nanoparticles for therapeutics one should also evaluate the effect on cellular metabolism and fate that can be attained via optimal conjugation with (bio)molecules of interest.

DDSs can improve the properties of free drugs by increase their in vivo stability and biodistribution, solubility and even by modulation of pharmacokinetics, promoting the transport and even more important the release of higher doses of the drug in the target site in order to be efficient $[18,22,37,38]$.

DDSs can be constructed by direct conjugation with the drugs and further surface modifications can lead to a better delivery for such systems, promoting a targeted delivery to specific types of cells and reaching cell compartments such as nucleus and mitochondria [15, 39]. As far as drug delivery is concerned, the most important nanoparticle platforms are liposomes, polymer conjugates, metallic nanoparticles (for example AuNPs), polymeric micelles, dendrimers, nanoshells, and protein and nucleic acid-based nanoparticles (for a more complete review see [40-42].

Among a wide variety of nanosystems, only a few nanomedicines, such as Doxil ${ }^{\circledR}(J a n s s e n$ Biotech Inc., Horsham, PA, USA), DaunoXome ${ }^{\circledR}$ (Galen US Inc., Souderton, PA, USA), Depocyt ${ }^{\circledR}$ (Pacira Pharmaceuticals Inc., San Diego, CA, USA), Genexol-PM ${ }^{\circledR}$ (Samyang Biopharmaceuticals Corporation, Jongno-gu, Seoul, Korea), Abraxane ${ }^{\circledR}$ (Celgene Corporation, Inc., Berkeley Heights, NJ, USA), Myocet巴 (Sopherion Therapeutics Inc., Princeton, NJ, USA) and Oncaspar® (Enzon Pharmaceuticals Inc., Bridgewater, NJ, USA), are approved for use in the treatment of cancer (for a review see [6]). 
The implementation of nanoparticles towards cancer treatment can be based in certain characteristics as their size, surface properties and the possibility of a variety of specific ligands in their surface [18]. The high surface properties and other physicochemical features of nanoparticles can be modulated for the development of valuable systems that detect tumor cells either qualitatively or quantitatively $[10,19]$.

Targeting the cancer cells occurs via two different strategies: passive targeting and active targeting $[4,43,44]$. The passive targeting of tumor cells by nanoparticles depends upon an EPR effect promoted by angiogenic vessels with defective vasculature and improper lymphatic flow, reaching a higher accumulation in tumor cells compared to normal cells [15]. The increased accumulation of a drug in the tumor interstitium achieved by nanoparticles can be more than ten times higher compared to the drug alone [4]. This type of deliver is based in nanoparticle's half-time of circulation on the bloodstream, size and surface properties, and even depends on the degree of angiogenesis [45]. Despite the increased drug accumulation inside the tumor, this strategy rise some concerns about the targeting specificity of such mechanism based in the controversial influence of the EPR effect on drug externalization, which promotes a widespread distribution all over the tumor $[4,46]$. The lack of specificity of such targeting led to further innovation with the implementation of an active targeting, which is achieved by the functionalization of nanoparticle's surface with a plethora of functional moieties such as antibodies and other biomolecules that recognized the specific surface antigens or specific biomarker of tumor cells [4,44]. The targets choice depends on its high abundance in cell surface and its unique expression, and consequently the capacity of internalization of the nanoconjugate $[4,47,48]$. Although it is considered that active targeting does not have a direct association to the total nanoparticles accumulated within the tumor, it will influence the uptake of nanoparticles via receptor-mediated internalization and improve the efficiency of anti-tumor agents that have intracellular targets [49, 50]. Active targeting can be the potential way of polymeric nanoparticles to deliver chemotherapeutic drugs to cancer cells and is, therefore, one of the main vectors of DDS development at present involving tailoring of nanoparticles to deliver the effective cargo without compromising the selective targeting.

\section{Gold Nanoparticles (AuNPs)}

Metallic nanostructures are more flexible particles compared to other nanomaterials owed to the possibility of controlling the size, shape, structure, composition, assembly, encapsulation and tunable optical properties [51,52]. Between the metallic nanostructures possible applied, AuNPs appears of great interest in the medical field, 3showing great efficiency towards cancer therapy [51-54]. The continuous interest in AuNPs is based in their tunable optical properties that can be controlled and modulated for the treatment and diagnosis of diseases $[9,54,52]$.

\subsection{Synthesis, functionalization, characterization and properties of AuNPs}

The synthesis of nanoparticles follows some aspects relying in a high homogeneity of the materials in physical properties that greatly influence the size, shape and surface characteris- 
tics. The main process for nanoparticles development requires chemical administration of capping agents that adsorb in the surface of nanoparticles ([55] and references therein). AuNPs can be synthesized with different sizes through the reduction of gold with different agents such molecules bearing a thiol group, an aliphatic chain and a charged end group, and that can avoid particle aggregation [37]. Furthermore, this dense layer of stabilizing agent promotes a general change in the surface charge of AuNPs allowing ligand exchange with several molecules, promoting AuNPs functionalisation and then an increase in particle stability in physiological environments $[55,56]$. AuNPs deliver systems can be formulated based in their capacity to bearing different functional groups, once it can be involved in covalent and noncovalent bindings by a thiol-linker $[37,55]$. In fact, robust AuNPs appear by the stabilization with thiolates once the bond between $\mathrm{Au}$ and the thiol (S) is very strong [57]. This process enhances the affinity of the AuNPs surface for several types of ligands such as polyethylene glycol (PEG) molecules, nucleic acids (DNA and RNA), peptides, antibodies, and also small drug molecules (Figure 2) [9, 13, 37, 47, 52, 56, 57].

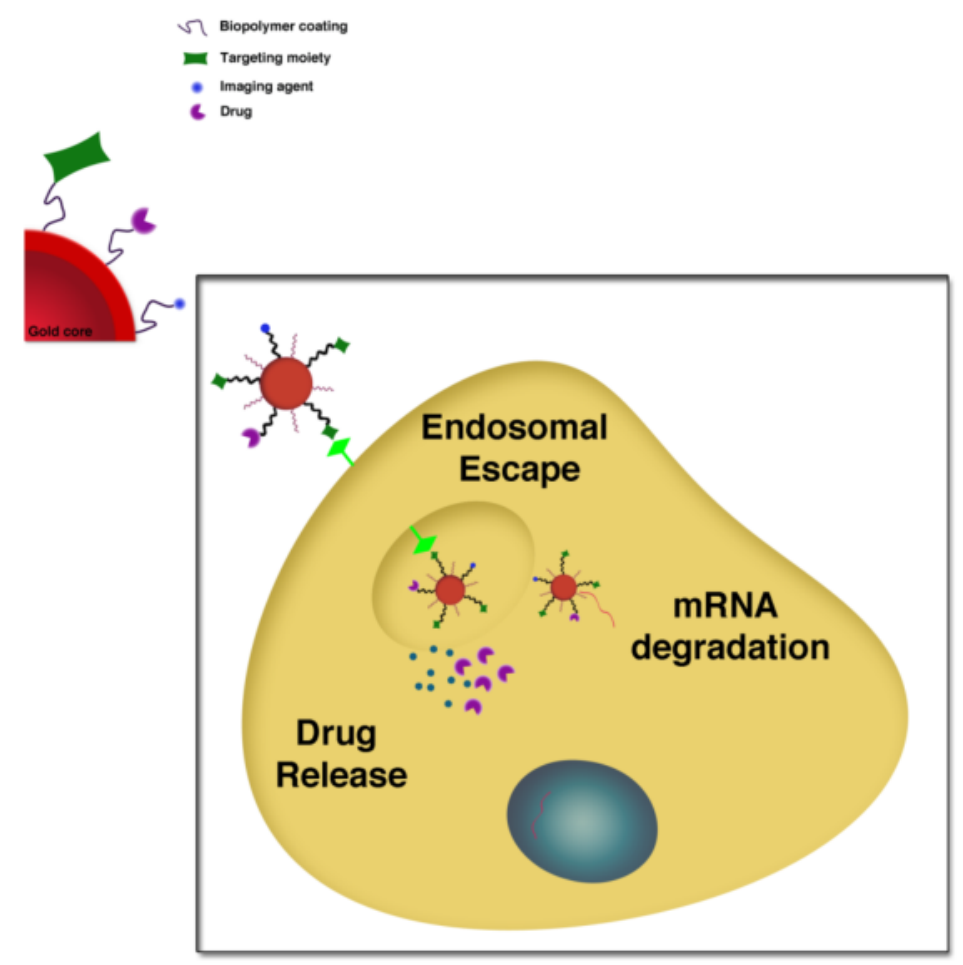

Figure 2. Multifunctional NP-based systems for tumor targeting, delivery and imaging. These innovative NPs comprise a targeting moiety, a silencing moiety and anticancer drug molecules for delivery to the target tissue. Depending on the targeting mechanism, they can be on the surface or inside the NPs. Multifunctional systems can carry reporter molecules tethered to the particle surface and employed as tracking and/or contrast agents. 
Most passive targeting AuNPs have a surface coated with PEG for biocompatibility and "stealth" purposes [58]. Importantly, it should be noted that increased hydrophilicity on the AuNPs surface can impede its uptake by cancer cells, thereby hampering efficient drug delivery to tumors by passive targeting nanoparticles $[58,59]$.

As far as the targeting approach is concerned, one key issue relies on the choice of optimal targeting ligands, possibly by balancing their stoichiometry in comparison with the antibiofouling surface of AuNPs. More specifically, two important ligand properties, ie, affinity and density, can have a key role in effective targeting of nanoparticles to the cell surface membrane. Again, the ligand binding affinity is the result of the equilibrium between enthalpic advantages (for ligand-receptor interaction) and entropic losses (stretching, flexibility, or compressibility of the nanosystem). For example, greater ligand density does not necessarily lead to a higher intracellular concentration, given the decrease in "stealth" surface characteristics. Moreover, although the uptake of AuNPs usually increases with an increasing+/- charge ratio of nanoparticles (in terms of zeta potential values), an excess positive charge can induce toxicity and promote an immunologic reaction. Therefore, the optimal ligand density and charge on the AuNPs surface should be investigated on a case-by-case basis. AuNPs can be incorporated into larger structures such as polymeric nanoparticles or liposomes that deliver large payloads for enhanced diagnostic applications, efficiently encapsulate drugs for concurrent therapy or add additional imaging labels. This array of features has led to their application in biomedical fields, but more recently in approaches where multifunctional gold nanoparticles are used for multiple methods, such as concurrent diagnosis and therapy, so-called theranostics [53, 60-63].

AuNPs characterization is based on UV-Vis spectroscopy for the determination of the surface plasmon resonance (SPR) of the metallic gold, Transmission Electron Microscopy (TEM) for the determination of the average size of the particles, Scanning Electron Microscopy (SEM) for the characterization of the morphological features and Atomic Absorption Spectrometry that quantify the amount of gold [64]. AuNPs biodistribution can be monitored before the delivery of its payload which allows the establishment of treatment plan [65].

The application of AuNPs for in vitro diagnosis, in vivo imaging, therapy and also as DDSs relies in their chemical stability, high solubility in water, suitable morphology and limited dispersiiity, high surface-to-volume ratio, non-toxicity in biologic systems and an easy synthesis and functionalisation with a plethora of biomolecules (targeting and also silencing moieties) and drugs (Figure 2) [19, 21, 55, 56, 66-68].

\subsection{AuNPs in cancer therapy}

\subsubsection{Photothermal therapy}

AuNPs formulations gain a major impact in cancer therapy in different contexts based in their properties that gain particular interest given some cancer specificities. AuNPs presents tunable optical properties that allow the absorption of light at near UV to near infrared, being the last one a characteristic that allows nanoparticles to enter cells, constituting a major breakthrough for its application in photothermal therapy or hyperthermia [57, 69]. This is thought due to the fact that increasing temperature of the cells above $42^{\circ} \mathrm{C}$ lead to a loss of cell viability [5]. Thus, 
nanoparticles heat up after irradiation of the body or local area with a magnetic field or another source of energy and consequently induce an increase in cancer cells temperature until cell death [5]. Several gold nanostructures are being referred as successful candidates as photothermal agents, such as the case described by Sirotkina and coworkers where AuNPs reach a high concentration in the skin tumor tissue and lead to an apoptotic response [70]. AuNPs compared to the simple irradiation method, the laser hyperthermia (a methodology though to circumvent the side effects associated to the current cancer therapies), has an advantageous of needing less irradiation energy to promote tumor ablation [57].

\subsubsection{Radiotherapy}

AuNPs have been review in radiotherapy experiments in order to overcome the problems associated to the healthy tissue damage imposed by radiotherapy [5,57]. This strategy is based in the well-known accumulation of AuNPs in the tumor that will be acting as a decoy to focus the radiation in the tumor and limit its action in normal tumor vicinity, being able to decrease the initial quantity of radiation administrated [5, 71, 72]. A long term study using AuNPs and irradiation in mices bearing implanted tumors in order to eliminate the possibility of tumor regression, results in a reduction of the tumor size until not be detected and $86 \%$ long term cure, i.e. for more than a year, which was much higher than the $20 \%$ survival for the implementation of just radiotherapy [65].

\subsubsection{Angiogenesis inhibition}

The inhibition of angiogenesis, i.e. the formation process of new blood vessels, is also a potent mechanism by which AuNPs can operate for cancer therapy [57, 73]. AuNPs have the ability to prevent phosphorylation of the proteinsinvolved in this process of angiogenesis, by their binding to the cysteine residues in heparin-binding growth factors [73]. Complementary, the AuNPs intravenously administrated can be irradiated which leads to endothelium damage and then a break in the oxygen and nutrient supply to the tumors involved, another way of angiogenic therapy [65]. Radiotherapy, once have a major impact in rapidly divided cells, presents reduced activity towards the niche of central cells that become independent of blood supply and then hypoxic and with reduced proliferation capacity, leading to a continuous survival of such cells, which is the main cause of tumor relapse [65]. So the complete abolish of angiogenesis is a potential strategy to eradicate these cancer cells and then eradicate cancer [65].

\subsection{AuNPs as delivery systems}

The well-known application of AuNPs in cancer therapy described above, lead to further investigation of new potential therapeutic strategies and was verified that AuNPs can be used in the design of delivery systems [74, 75]. The motivation for the implementation of AuNPs as drug delivery platforms is built in their easy to synthesis, functionalisation and also great biocompatibility, demonstrating that functionalisation with specific payloads have a great potential to destroy cancer cells [15, 76]. As described above, AuNPs as a potential nanocarrier have the possibility to carry different payloads, such as small drug molecules for drug delivery or biomolecules like DNA, proteins and RNA (siRNAs), being recognized as an attractive gene 
delivery system (Figure 2) [37]. The conjugation of the two types of therapeutic functions in nanoparticles, i.e. a cytotoxic drug and a specific cancer cell target moiety, act as a single platform in a synergetic way to promote a higher affinity to cancer cells in order to signaling them to the efficiently release of the anticancer agent, circumventing the biological and biophysical barriers $[23,5,77]$.

\subsubsection{Specific targeting}

Nanoconjugates for drug delivery can accommodate a myriad of anti-cancer molecules that will be release and have its therapeutic effects in cancer cells, however healthy tissues can also be affected and to avoid this problem a targeting strategy is an important feature for combined therapy [78]. Taking advantage of tumor molecular markers as docking sites to concentrate the therapeutic effect at tumors, it is possible to increase therapeutic efficacy while reducing systemic exposure and off-target effects. Several of these tumor molecular markers are surface proteins/receptors present in cancer cells and in tumor vasculature that are not expressed or are expressed at much lower levels in normal cells, thereby distinguishing tumor masses from the surrounding normal tissues [79]. For a selective and with great potential delivery systems based in nanoparticles it is needed an efficient targeting to uniquely overexpressed receptors in cancer cells [76]. The potency of such systems is achieved by the enhancement of cellular accumulation of AuNPs by an active targeting to cancer cells compared to a free drug that passively enters the cells, which simultaneously avoid the biological response and biophysical barriers in vivo $[5,80]$. In fact, nanoparticles need to continue in the bloodstream for enough time and cannot be eliminated in order to target the tumor site in the body, and surface modifications can be a useful property to avoid the mononuclear phagocytic system [4].

Based in this specificity, this platform can be a potential methodology for cancer therapy once it can differentiate with high certainty between cancer cells and non-cancer cells, one major concern related to the current cancer therapies [5, 81]. The increase of the surface area of AuNPs associated with other features such as distance-and refractive index-spectroscopic properties appears important for the construction of relevant biodetection molecules [55]. This capacity of AuNPs can be exploited for the improving of the therapeutic capacity of such systems, once the application of diagnostic and therapeutic strategies at the same time, Theranostics, can lead to a greater release at a specific tumor site, the targeting moiety or the drug, and it can be tracking in the whole body [82].

There are several types of tumor-targeting biomolecules such as peptides like RGD [47], proteins (transferrin, epidermal growth factor (EGF)) and carbohydrates [5], oligonucleotides such as aptamers [83], and monoclonal antibodies [85-87]. For example, the anti-epithelial growth factor receptor (EGFR) monoclonal antibody has been used as an active targeting agent, since EGFR and its ligands are commonly overexpressed in a variety of solid tumors [86-88].

Functionalization of AuNPs with specific ssDNA molecules (Au-nanoprobes) concerns a great detection system for specific DNA targets, being a rapid, sensitive, specific and inexpensive system [19]. For example, cancer cells overexpressing the folate receptors can be specifically targeted by AuNPs functionalized with folate ligands, and then the chemotherapeutic agent Doxorubicin (DOX) can be release into them and induce a higher toxicity compared to the one 
in healthy cells (do not express these receptors) and when compared to the DOX alone [89]. Additionally, the cell-surface specific markers that characterize the CSC pool constitute a way for targeting those cells in the whole tumor $[7,8]$. Therapeutic strategies need to be focused in this specific CSC niche instead of the rapidly divided in order to prevent tumor regression $[7,8]$.

The targeting of tumor angiogenic vessels is also gaining increased attention, as it may improve therapeutic efficiency in cases where tumor cells are less accessible [79]. In combination with passive targeting strategies, active targeting may enhance receptor-mediated endocytosis of the AuNP conjugates in target cells $[80,90]$. The intracellular localization of effector molecules can be further directed with the use of cell-penetrating peptides, which are short peptides that facilitate the delivery of various cargoes to cells, or with nuclear localization sequences, which direct cargos to the nucleus [91, 92]. Decorating AuNPs with proton sponge groups or using photothermal heating can further assist escape from endosomal sequestration/degradation [93]. Active targeting by AuNPs [94-96] has been shown to result in greater tumor accumulation than passive targeting, when AuNPs are administered systemically in vivo (6-13\% versus $2-5 \%)[94,95]$.

\subsubsection{AuNPs for drug/cargo delivery}

The construction of DDSs depends on size, charge and surface functionalities of the AuNPs, once they dictate the uptake capacity of such nanovectorization systems as well as its intracellular fate $[5,75]$. The possibility to functionalize AuNPs with a plethora of different cargos allows the development of several distinct approaches for drug delivery [76]. Moreover, stable nanovectorization systems in the blood-stream, drug release rate and clearance of the vector are two other important properties for the use of nanoparticles as DDSs [5, 57]. The use of vectorisation systems based in nanoparticles reveal the capacity to transpose the biological barriers imposed, with the release of low molecular-weight molecules that rapidly diffuse into the body, promoting a selective distribution towards cancer cells [5].

The active release of the drug into cells depends on the interaction between the drug and AuNPs (covalent or non-covalent binding) and even on methods of release after reaching the cells [76]. Non-covalent binding, such as the one used for hydrophobic drugs, does not need further alterations to the drug in order to be released [97] while for covalent interactions, establish for prodrugs, it implies the application of an internal or external mechanisms [98, 99]. The tunable optical properties of AuNPs surface is a prominent feature for the release of a drug either by internal or external stimuli [5]. External stimuli can be administrated by a photo-regulated release, which depends on the administration of light to photo-cleavage of nanoparticles-drug interaction to activate the drug once free [100-102], like was demonstrated with AuNPs functionalized with 5-fluorouracil [103]. You and collaborators [104] reported that up to $60 \%$ of a doxorubicin payload could be loaded onto hollow gold nanospheres because the drug molecules were adsorbed to both the inner and the outer surfaces of the hollow gold nanospheres via electrostatic attraction. Owing to the strong SPR absorption of novel gold nanostructures, drug release can be activated by NIR light [104, 105]. Glutathione can be a good internal stimulus of release for covalent interactions, by exchange reactions between 
disulfide of AuNPs and the intracellular glutathione [75]. AuNPs loaded with doxorubicin have been shown to be able to reverse cancer cells' resistance to the drug [106].

AuNPs with a high surface area attractive to establish interactions to a plethora of platinum drugs have been described [107]. Brown and coworkers designed a platinum-tethered AuNP system bearing the active compound of oxalipatin as its platinum molecule, and tested its platform in lung and colorectal cancer cell lines, demonstrating a more cytotoxic effect compared to oxaliplatin alone and also a higher accumulation of the active compound in those cancer cells reaching the nucleus for possible DNA interaction, what constitute a good delivery system [107].

\subsubsection{AuNPs for gene therapy}

Gene therapy is though as a hopeful strategy in cancer therapy being considered as a powerful treatment like chemotherapy and radiotherapy, however the implementation of such systems is based in viral vectors that raise cytotoxic and immune response problems [57, 108]. When conjugated to AuNPs, siRNAs have been shown to exhibit increased stability, cellular uptake and efficacy in physiological conditions, retaining the ability to act through the RNAi pathway $[109,110]$. The first demonstration that DNA-AuNP conjugates could be easily internalized into cells, without the need for transfection agents, and induced gene silencing by an antisense mechanism was reported by Rosi and co-workers in 2006 [111]. AuNPs as gene-delivery vectors emerged initially with cationic ligands that appears a good gene delivery system once protects the DNA molecule from degradation by DNAse I [112]. Han and coworkers have identified that cationic AuNPs can trigger DNA release into cells by glutathione intracellular concentrations [113].These remarkable studies prompted others to use AuNPs as siRNA delivery systems and contributed to the development of many strategies to improve intracellular siRNA delivery in vitro and in vivo. These strategies can be grouped into two major categories that are currently used for tethering siRNAs to AuNPs, namely (1) the gold-thiol bond and (2) electrostatic interactions. Both categories involve, in some way, the use of poly(ethylene glycol (PEG) or other passivating agents for stabilization and to promote endosomal escape of the AuNP conjugates into the cell cytoplasm [114].

The silencing of cancer-related molecules can be addressed by this delivery platform, being of major concern the oncogenes that have specific involvement in cell survival and proliferation [115]. siRNAs can be pointed as potential therapeutic molecules once its function relies in the suppression of gene expression [78]. siRNA molecules present limitations when administrated alone: do not cross the cell membrane, are rapidly degradable by endo-and exo-nucleases, have low stability in the blood and induces systemic toxicity [116]. Nanoparticles functionalized with siRNAs that have been tested for targeting reporter genes in in vitro cell cultures and recently AuNPs functionalized with siRNAs were investigated for in vitro and in vivo targeting genes $[67,116]$. AuNPs can in fact be a good system for antisense and siRNA delivery since they can protect these molecules from degradation [109]. Thus, in order to improve cytoplasmatic translocation of siRNAs and promoting a complete gene silencing, is of utmost important the formulation of these nanoconjugates with siRNAs once its smaller size can potentiate and improve the interactions between biomolecules in the surface or into a cell $[4,116]$. 
In vivo studies using this system are still scarce, alerting us for the need to overcome remaining barriers that prevent its translation into the clinics. Some recent studies are highlighted. Zhang and co-workers have developed an anti-metastasis therapy consisting of gold nanorods (AuNRs) conjugated electrostatically with siRNAs, which targeted the protease-activated receptor 1 (PAR-1) [117]. These conjugates were then delivered to highly metastatic human breast cancer cells. The authors observed efficient downregulation of PAR-1 mRNA and protein levels and decreased metastatic ability of the cancer cells [117]. By allowing any short nucleic acid to be hybridized to the cargo DNA covalently linked to the AuNP, the former can be designed for a specific purpose, such as gene knockdown, redirection of alternative splicing, and modulation of signal transduction pathways, Ryou and collaborators delivered shRNAs targeting the Mcl-1L mRNA to a xenografted tumor in a mouse model, and showed a $5 \%$ reduction in protein expression which was sufficient to induce apoptosis of the xenograft tumor cells [118]. These studies did not include a targeting strategy because they were performed either in vitro or in vivo by directly injecting the conjugates into tumors. However, for systemic delivery, an additional targeting moiety is generally required to improve treatment efficacy and reduce off-target effects. Lu and co-workers [93] used Au nanocages targeted to folate receptors (overexpressed in many types of cancer) and carrying a siRNA against the NFkBp65, which encodes a transcription factor highly involved in tumor formation and progression. They injected these constructs intravenously into in nude mice bearing HeLa cervical cancer xenografts and observed a significantly higher tumor uptake of the targeted conjugates compared to the non-targeted ones. They additionally took advantage of the photothermal properties of the Au nanocages to achieve a controlled cytoplasmic delivery of siRNA upon NIR light irradiation and observed efficient NF-kappaB p65 downregulation only when tumors were irradiated with NIR light [93].

AuNPs functionalized with c-myc siRNAs were studied in a cervix adenocarcinoma cell line and demonstrate a great accumulation in the cytoplasm of the tumor cells and an evident ability to silencing the $c-m y c$ oncogene [67]. They functionalized AuNPs with PEG, cell penetration (TAT) and cell adhesion peptides (RGD, which binds to the integrin $\alpha \mathrm{V} \beta 3$ receptor family) [119], and c-myc targeting-siRNAs [5]. They have also shown in a more recent study that these same nanoconjugates are capable of targeting tumor cells in a lung cancer murine model and of inducing significant downregulation of the c-myc oncogene, followed by tumor growth inhibition and prolonged survival of lung tumor bearing mice [116].

Furthermore, miRNAs can appear with aberrant patterns of expression in tumors and then be related to its development, progression and tumor differentiation [47]. miRNAs can act as oncogenes or tumor suppressor genes accounting to its deregulation in cells, then it's downregulation or up-regulation respectively, can be a major breakthrough for cancer therapy [120]. Conde and coworkers revealed a platform based in Au-nanobeacons to targeting and efficiently silencing miR-21, an oncogenic miRNA commonly up-regulated in almost all types of cancers $[47,121]$.

This targeting approached can also become a potential strategy to overcome the problem of multidrug resistance of cancer cells to the application of several drugs (Fernandes and Baptista, 2014). One of the major mechanisms of multidrug resistance in cancer is associated to ATP- 
binding cassette $(\mathrm{ABC})$ membrane transporters, such as P-glycoprotein (P-gp), and others efflux pumps such as BCRP, which imply these as potential targets of silencing for cancer therapy $[122,123]$. Cancer stem cells (CSCs) can also express these membrane proteins which confer to this subpopulation resistance to the current chemotherapeutic agents $[123,124]$. Thus, the implication of a silencing strategy towards these cancer related genes evolve in order to minimize cancer resistance barriers to the actual therapy and then obtain an efficient response towards the chemotherapeutic agents applied [115, 125]. It was demonstrated by a system of lipid-modified dextran nanoparticles bearing siRNAs towards $A B C B 1$ gene (P-gp), that this approach can efficiently deliver the siRNA molecule and reduces the expression of P-gp although at the same order of greatness as the siRNA alone [126]. This reveals the necessity to continuously develop nanoparticles systems that can target and silencing these genes and proteins.

Another multidrug resistance mechanism is associated to the capacity of cancer cells to evade apoptotic response, when resistance induced by efflux pumps is not seen [127]. Apoptosis is the major cellular process induced by chemotherapeutic agents, so cancers bearing apoptosis defects cannot be efficiently treated by those agents, then discovery of the molecular basis of such system can formulate novel therapeutic approaches [127, 128]. For example, the antiapoptotic protein $\mathrm{Bcl} 2$ is considered a proto-oncogene, and nano-based vector delivery systems has been establish with great efficacy towards this molecule [127, 129].

\section{Toxicity of AuNPs}

One major concern regarding AuNPs application in medical field relies in its toxicity in the biological systems, i.e. the production of a general toxicity response not only in cancer cells but also reaching healthy cells at the vicinity [78]. Taken into account the size, surface modifications and solubility in promoting biocompatibility of the nanovectorization systems, they can be safer to apply in the medical field to the treatment of cancer [130]. In fact, nanoparticles size is an important feature because it turns possible to circumvent the immune response and renal clearance, which maintains the therapeutic capacity of such systems [5].

Toxicity of AuNPs is generally accepted to be dependent on particle size, shape, and surface charge and chemistry [131-134]. However, it is thought that once AuNPs have a smaller size, approximately the size of biomolecules, it can be taken like one and then evade cellular barriers, with access to different tissues, and in the end can lead to the disruption of cell biological processes $[75,135]$. A control of the size dependent cytotoxicity of AuNPs, revealed that AuNPs with a 1-2 nm size represents more toxicity towards four cancer cells lines compared to AuNPs with $15 \mathrm{~nm}$ that do not display any toxicity (Pan et al., 2007). Additionally, the main organs affected by AuNPs are the liver and the spleen (Sun et al., 2011). Also, very small particles (1.4 and $5 \mathrm{~nm}$ in diameter) seem to be capable to enter the nucleus, where they can interact with DNA and cause molecular disturbance [136, 137]. Larger particles (16 nm and $33 \mathrm{~nm})$ are retained in endosomes and accumulate in the periphery of the nuclear region [138, 139]. At least three different studies reported that cellular uptake of AuNPs reach maximum levels for 
a particle size of about $50 \mathrm{~nm}$ [140-142]. Also, surface functionalisation seem to be capable of inducing higher level of apoptotic cell death, probably related to increased cell uptake when compared to unmodified $40 \mathrm{~nm}$ AuNPs [141]. According to data from in vitro studies, AuNPs' toxicity is believed to result mainly from the induction of oxidative stress [143-145]. Indeed, up-regulation of stress related genes was found to result from cell exposure to AuNPs, which also promoted the down-regulation of cell cycle related genes [145-147]. Nevertheless, most of these studies paid little attention to genome damage, such as DNA strand breaks and nuclear abnormalities, or characterization of protein markers for toxicity. An integrated toxicology evaluation encompassing DNA damage, stress related enzymes and a proteome profiling approach showed no significant cytotoxicity of PEGylated AuNPs and no up-regulation of proteins related to oxidative damage [148]. Nevertheless, previous studies using metallic nanoparticles showed acute toxicity, mainly by the introduction of damages to the DNA molecule and also by oxidative damage [146, 149, 150].

AuNPs are however generally considered a system that do not cause acute or adverse toxicity, and then are been taken as safer systems for therapeutic use [135]. AuNPs demonstrate to be a safe system due to their easy of functionalization [151]. This ideal is based in the assumption that gold nanoparticles do not lead to any effect in the cell, and instead, the function moiety in its surface promote the cytotoxic effect expected [139]. In the other way, expression studies revealed an overexpression of stress and inflammation related genes after AuNPs treatment, being associated to the action of AuNPs in oxidative stress induction [75]. A decrease in cell cycle genes expression was simultaneously observed, which symbolizes an irreversible damage that leads to cell death by necrosis [75].

Nanoparticles surface composition is another relevant point when talking about toxicity of nanoparticles systems [5]. The ligands and surface capping agents of AuNPs as the first line of contact with the different actors in the cell pathways can promote toxicity that in the end represents the overall toxicity associated to these nanoconjugates [5]

Also, both positive and negatively charged AuNPs were found to be similarly more cytotoxic against human keratinocytes (HaCaT cells) when compared to neutral AuNPs, with LD50 values of roughly half of those determined for the latter [152]. Despite the disruption in cell morphology and the dose-dependent toxicity observed for all three types of AuNPs, both anionic and cationic AuNPs induce mitochondrial stress and apoptosis in opposition to the necrotic cell death caused by neutral particles [152]. Another in vitro study comparing positive and negatively charged AuNPs reported that cationic NPs were far more toxic to Cos- 1 cells, human red blood cells and E. coli than anionic NPs, possibly as a result of cell lysis, as shown by a dye leakage technique [133]. However, Alkilany and co-workers clearly showed that serum proteins become readily adsorbed to the surface of charged NPs, inducing an inversion of surface charge in particles that were originally cationic [153]. This would reduce electrostatic interaction between the original positive NPs and the negative cell membrane, the first step towards cell lysis mediated toxicity of cationic NPs [133].

Regarding in vivo experiments, several studies have demonstrated that AuNPs of $50 \mathrm{~nm}$ and larger were non-toxic to mice, conversely to what has been observed for AuNPs $<40 \mathrm{~nm}$ [54, 55]. In fact, there are concordant data from different studies on the biodistribution and 
accumulation of AuNPs in mice showing that most of the intravenously injected nanoparticles are retained in the liver, regardless of their size [156-158]. There is also an agreement in that AuNPs have the ability to transpose the blood-brain barrier and thus reach the brain, with a cut-off limit in diameter of around $20 \mathrm{~nm}$ [159], and that smaller particles have the most widespread organ distribution [156-158]. Organ distribution seems to be ruled by a more or less complex relationship with nanoparticle size. For instance, it is known that renal excretion of AuNPs is maximized for a narrow size range of 6-8 nm, resulting in an accelerated clearance rate [160]. Despite the valuable use of animal models, the effect of size on the toxicity of AuNPs in humans is difficult to predict since the size of endothelial cells' fenestrae is highly variable between individuals, thereby affecting nanoparticle clearance [75]. Therefore, more consistent data on the toxicological profile of AuNPs in vivo is necessary. For a more complete review on biodistribution, encompassing earlier studies and administration routes other than intravenous injection, see Khlebtsov and Dykman [159]. Furthermore, core size, charge and surface chemistry of AuNPs seems to correlate to toxicity on the development of zebrafish embryos, with positive and negatively charged AuNPs causing mortality and malfunctions to the embryos, respectively [161]. Adverse effects were also found in the model system Drosophila melanogaster after exposure to citrate-capped AuNPs, which were shown to reduce fertility in a dose-dependent manner and also the life span [144, 162].

Nonetheless, long-term studies in higher organisms are necessary to further characterise the safety of AuNPs as therapeutic agents, so they can be safely administrated to humans without concerns about late toxicity symptoms.

\section{Conclusions \& future}

Cancer is a complex disease with a plethora of cell types and differentiation stages that trigger standard molecular mechanisms towards recruitment of cells and nutrients to enhance survival and proliferation. Cancer complexity is also dependent from the specific and multifaceted umor microenvironment. All these different molecular pathways, mechanism and markers can be used as potential targets for therapeutics. However, current therapeutics (drugs and molecules) show serious cell toxicity that is not merely directed at the cancer cells but instead promote off-target cellular disarray and cell death, usually reported ad undesirable side effects and systemic toxicity.

Nanomedicine has been putting forward several therapeutic concepts that disrupt the way we have been dealing with cancer therapy, i.e. nanoparticles as drug delivery agents, minimising side effects and toxicity of the drugs. Furthermore, these nanoparticle platforms allow for selective targeting of cancer cells or tumor vessels either by incorporating novel or standard anticancer drugs and/or the delivery of therapeutic genetic modulators. These approaches, often based on the robustness and chemical properties of AuNPs, have shown great promise in preclinical models. Some recent advances in ligand-targeted NPs have begun to demonstrate improvement in cancer therapy. 
What is more, many tumors become resistant to drugs, requiring that novel strategies involving drug targeting vehicles that deliver high concentrations of combinatorial therapeutics to the selected targets. For this to happen, it is crucial that these nanoconjugates are capable to withstand the body's clearance and reaction to non-self particulates. The robustness of AuNPs as target delivery platforms will be achieved when reticuloendothelial system clearance is avoid and occur an enhance of the endothelial penetration, once the first one can lead to a longer time in circulation and the second leads to an increase of targeting and drug accumulation (Kumar et al., 2013).

The use of multiple nanoparticles that can be used together may overcome current limitations of each individual nanoformulation alone. For example, AuNPs have proven to be outstanding vectorisation systems for gene delivery and can be used to target molecular pathways, including those involved in drug resistance and in survival of cancer cells. These NPs may be used in combination with any other polymeric and/or metallic nanoparticles in therapeutic approaches that include drug and thermal ablation, selective delivery via out of the boy triggering (light source).

All of these applications of AuNPs in therapeutics still lack enough toxicology and pharmacology studies and data that can support the effective translation into the clinics. However, the efficacy in fighting cancer cells shows that the effort to push forward with the needed regulatory requirements and compliance is worth pursuing since the enhanced properties allow for outstanding improvements to biocompatibility, circulation and therapeutic response.

\section{Acknowledgements}

The authors acknowledge Fundação para a Ciência e Tecnologia (FCT/MEC) for funding: CIGMH (PEst-OE/SAU/UI0009/2011); PTDC/BBB-NAN/1812/2012.

\section{Author details}

Joana Silva ${ }^{1}$, Alexandra R. Fernandes ${ }^{1,2}$ and Pedro V. Baptista ${ }^{1,3^{*}}$

*Address all correspondence to: pmvb@fct.unl.pt

1 Department of Life Sciences, Faculdade de Ciências e Tecnologia, Universidade Nova de Lisboa, Portugal

2 Centro de Química Estrutural, Instituto Superior Técnico, Lisboa, Portugal

3 CIGMH, Departamento de Ciências da Vida, Faculdade de Ciências e Tecnologia, Universidade Nova de Lisboa, Campus de Caparica, Portugal 


\section{References}

[1] Jemal A, Bray F, Center MM, Ferlay J, Ward E, Forman D. Global cancer statistics. CA: A Cancer Journal for Clinicians 2011;61(2): 69-90.

[2] Blanco E, Hsiao A, Mann AP, Landry MG, Meric-Bernstam F, Ferrari M. Nanomedicine in cancer therapy: Innovative trends and prospects. Cancer Science 2011;102(7): 1247-1252.

[3] Peer D, Karp JM, Hong S, Farokhzad OC, Margalit R, Langer R. Nanocarriers as an emerging platform for cancer therapy. Nature Nanotechnology 2007;2(12): 751-760.

[4] Baptista PV. Cancer nanotechnology-prospects for cancer diagnostics and therapy. Current Cancer Therapy Reviews 2009;5(2): 80-88.

[5] Conde J, Doria G, Baptista P. Noble Metal Nanoparticles Applications in Cancer. Journal of Drug Delivery 2012;2012(2012): 1-12.

[6] Sanna A, Pala N, Sechi M. Targeted therapy using nanotechnology: focus on cancer. International Journal of Nanomedicine 2014;9: 467-483.

[7] Clarke MF, Dick JE, Dirks PB, Eaves CJ, Jamieson CHM, Jones DL, Visvader J, Weissman IL, Wahl GM. Cancer Stem Cells-Perspectives on Current Status and Future Directions: AACR Workshop on Cancer Stem Cells. Cancer Research 2006;66(19): 9339-9344.

[8] Jordan CT, Guzman ML, Noble M. Mechanisms of Disease: Cancer Stem Cells. The New England Journal of Medicine 2006;355(12): 1253-1261.

[9] Fernandes AR, Baptista PV. Nanotechnology for Cancer Diagnostics and Therapy An Update on Novel Molecular Players. Current Cancer Therapy Reviews 2014;9(3): $1-9$.

[10] Brigger I, Dubernet C, Couvreur P. Nanoparticles in cancer therapy and diagnosis. Advanced Drug Delivery Reviews 2012;64: 24-36.

[11] Oerlemans C, Bult W, Bos M, Storm G, Nijsen JFW, Hennink WE. Polymeric Micelles in Anticancer Therapy: Targeting, Imaging and Triggered Release. Pharmaceutical Research 2010;27(12): 2569-2589.

[12] Larsen AK, Escargueil AE, Skladanowski A. Resistance mechanisms associated with altered intracellular distribution of anticancer agents. Pharmacology \& Therapeutics 2000;85(3): 217-229.

[13] Conde J, de la Fuente JM, Baptista PV. Nanomaterials for reversion of multidrug resistance in cancer: a new hope for an old idea?. Frontiers and Pharmacology 2013;4(134): 1-5. 
[14] Brannon-Peppas L, Blanchette JO. Nanoparticle and targeted systems for cancer therapy. Advanced Drug Delivery Reviews 2012;64: 206-212.

[15] Tiwari G, Tiwari R, Sriwastawa B, Bhati L, Pandey S, Pandey P, Barnnerjee SK. Drug delivery systems: An updated review. International Journal of Pharmaceutical Investigation 2012;2(1): 2-11.

[16] Ganta S, Devalapally H, Shahiwala A, Amiji M. A review of stimuli-responsive nanocarriers for drug and gene delivery. Journal of Controlled Release 2008;126(3): 187-204.

[17] Koo OM, Rubinstein I, Onyuksel H. Role of nanotechnology in targeted drug delivery and imaging: a concise review. Nanomedicine 2005;1(3): 193-212.

[18] Drbohlavova J, Chomoucka J, Adam V, Ryvolova M, Eckschlager T, Hubalek J, Kizek R. Nanocarriers for Anticancer Drugs-New Trends in Nanomedicine. Current Drug Metabolism 2013;14(5): 547-564.

[19] Baptista PV, Pereira E, Eaton P, Doria G, Miranda A, Gomes I, Quaresma P, Franco R. Gold nanoparticles for the development of clinical diagnosis methods. Analytical Bioanalalytical Chemistry 2008;391(3): 943-950.

[20] Silva GA. Introduction to Nanotechnology and Its Applications to Medicine. Surgical Neurology 2004;61(3): 216-220.

[21] Baptista PV. Could gold nanoprobes be an important tool in cancer diagnostics?. Expert Reviews of Molecular Diagnostics 2012; 12(6): 541-543.

[22] De Jong WH, Borm PJA. Drug delivery and nanoparticles: Applications and hazards. International Journal of Nanomedicine 2008;3(2): 133-149.

[23] Ganesh T. Improved Biochemical Strategies for Targeted Delivery of Taxoids. Bioorganic \& Medicinal Chemistry 2007;15(11): 3597-3623.

[24] Hu CMJ, Zhang LF. Therapeutic Nanoparticles to Combat Cancer Drug Resistance. Current Drug Metabolism 2009;10(8): 836-841.

[25] Nakanishi T, Fukushima S, Okamoto K, Suzuki M, Matsumura Y, Yokoyama M, Okano T, Sakurai Y, Kataoka K. Development of the polymer micelle carrier system for doxorubicin. Journal of Controlled Release 2001;74(1-3): 295-302.

[26] Ferrari M. Cancer nanotechnology: Opportunities and challenges. Nature Reviews Cancer 2005;5(3): 161-171.

[27] Kim BY, Rutka JT, Chan WC. Nanomedicine. The New England Journal of Medicine 2010;363(25): 2434-2443.

[28] Riehemann K, Schneider SW, Luger TA, Godin B, Ferrari M, Fuchs H. Nanomedicine - challenge and perspectives. Angewandte Chemie International Edition England 2009;48(5): 872-897. 
[29] Petros RA, DeSimone JM. Strategies in the design of nanoparticles for therapeutic applications. Nature Reviews Drug Discovery 2010;9(8): 615-627.

[30] Bae KH, Chung HJ, Park TG. Nanomaterials for cancer therapy and imaging. Moleculles and Cells 2011;31(4): 295-302.

[31] Taylor A, Wilson KM, Murray P, Fernig DG, Levy R. Long-term tracking of cells using inorganic nanoparticles as contrast agents: are we there yet? Chemical Society Reviews 2012;41(7):2707-2717.

[32] Villalonga-Barber C, Micha-Screttas M, Steele BR, Georgopoulos A, Demetzos C. Dendrimers as biopharmaceuticals: synthesis and properties. Current Topics in Medicinal Chemistry 2008;8(14): 1294-1309.

[33] Clift MJ, Stone V. Quantum dots: an insight and perspective of their biological interaction and how this relates to their relevance for clinical use. Theranostics 2012;2(7): 668-680.

[34] Yamashita T, Yamashita K, Nabeshi H, Yoshikawa T, Yoshioka Y, Tsunoda S, Tsutsumi Y. Carbon nanomaterials: efficacy and safety for nanomedicine. Materials 2012;5(2): 350-363.

[35] Lammers T, Kiessling F, Hennink WE, Storm G. Drug targeting to tumors: principles, pitfalls and (pre-) clinical progress. Journal of Controlled Release 2012;161(2): 175-187.

[36] Walkey CD, Chan WC. Understanding and controlling the interaction of nanomaterials with proteins in a physiological environment. Chemical Society Reviews 2012;41(7): 2780-2799.

[37] Ghosh P, Han G, De M, Kim CK, Rotello VM. Gold nanoparticles in delivery applications. Advanced Drug Delivery Reviews 2008;60(11): 1307-1315.

[38] Cai W, Gao T, Hong H, Sun J. Applications of gold nanoparticles in cancer nanotechnology. Nanotechnology, Science and Applications 2008;1: 17-32.

[39] Pissuwan D, Niidome T, Cortie MB. The forthcoming applications of gold nanoparticles in drug and gene delivery systems. Journal of Controlled Release 2011;149(1): 65-71.

[40] Pathak Y, Thassu D. Drug Delivery Nanoparticles Formulation and Characterization. Rijeka: PharmaceuTech Inc.; 2009. p1-393.

[41] Zhang L, Gu FX, Chan JM, Wang AZ, Langer RS, Farokhzad OC. Nanoparticles in medicine: therapeutic applications and developments. Clinical Pharmacology \& Therapeutics 2008;83(5): 761-769.

[42] Davis ME, Chen ZG, Shin DM. Nanoparticle therapeutics: an emerging treatment modality for cancer. Nature Reviews Drug Discovery 2008;7(9): 771-782. 
[43] Dinarvand R, de Morais PC, D’Emanuele A. Nanoparticles for Targeted Delivery of Active Agents against Tumor Cells. Journal of Drug Delivery 2012; 2012(2012): 1-2.

[44] Nie S. Understanding and overcoming major barriers in cancer nanomedicine. Nanomedicine 2010;5(4): 523-528.

[45] Allen TM, Cullis PR. Drug delivery systems: entering the mainstream. Science 2004;303(5665): 1818-1822.

[46] Stohrer M, Boucher Y, Stangassinger M, Jain RK. Oncotic pressure in solid tumors is elevated. Cancer Research 2000;60(15): 4251-4255.

[47] Conde J, Rosa J, de la Fuente JM, Baptista PV. Gold-nanobeacons for simultaneous gene specific silencing and intracellular tracking of the silencing events. Biomaterials 2013;34(10): 2516-2523.

[48] Gao H Yang Z, Zhang S, Cao S, Shen S, Pang Z, Jiang X. Ligand modified nanoparticles increases cell uptake, alters endocytosis and elevates glioma distribution and internalization. Scientific Reports 2013;3(2534): 1-8.

[49] Bartlett DW, Su H, Hildebrandt IJ, Weber WA, Davis ME. Impact of tumor-specific targeting on the biodistribution and efficacy of siRNA nanoparticles measured by multimodality in vivo imaging. PNAS 2007;104(39): 15549-15554.

[50] Kirpotin DB, Drummond DC, Shao Y, Shalaby MR, Hong K, Nielsen UB, Marks JD, Benz CC, Park JW. Antibody Targeting of Long-Circulating Lipidic Nanoparticles Does Not Increase Tumor Localization but Does Increase Internalization in Animal Models. Cancer Research 2006;66(13): 6732-6740.

[51] Huang X, Jain PK, El-Sayed IH, El-Sayed MA. Gold nanoparticles: interesting optical properties and recent applications in cancer diagnostics and therapy. Nanomedicine 2007;2(5): 681-693.

[52] Figueiredo S, Cabral R, Luís D, Fernandes AR, Baptista PV. 2014. Integration of Gold nanoparticles and liposomes for combined anti-cancer drug delivery. In: Seifalian A. (ed.) Nanomedicine; University College London (UK); 2014. Chapter 3; available from http://www.onecentralpress.com/nanomedicine/\#.

[53] Cobley CM, Chen J, Cho EC, Wang LV, Xia Y. Gold nanostructures: a class of multifunctional materials for biomedical applications. Chemical Society Reviews 2011;40(1): 44-56.

[54] Kumar A, Boruah BM, Liang XJ. Gold nanoparticles: Promising nanomaterials for the diagnosis of cancer and HIV/AIDS. Journal of Nanomaterials 2011;2011(2011): 1-17.

[55] Baptista PV, Doria G, Quaresma P, Cavadas M, Neves CS, Gomes I, Eaton P, Pereira E, Franco R. Nanoparticles in Molecular Diagnostics. In: Villaverde A. (ed.) Progress in Molecular Biology and Translational Science Elsevier Inc.; 2011. p427-488. 
[56] Dreaden EC, Austin LA, Mackey MA, El-Sayed MA. Size matters: gold nanoparticles in targeted cancer drug delivery. Therapeutic Delivery 2012;3(4): 457-478.

[57] Boisselier E, Astruc D. Gold nanoparticles in nanomedicine: preparations, imaging, diagnostics, therapies and toxicity. Chemical Society Reviews 2009;38(6): 1759-1782.

[58] Alexis F, Pridgen E, Molnar LK, Farokhzad OC. Factors affecting the clearance and biodistribution of polymeric nanoparticles. Molecular Pharmaceutics 2008;5(4): 505-515.

[59] Knop K, Hoogenboom R, Fischer D, Schubert US. Poly(ethylene glycol) in drug delivery: pros and cons as well as potential alternatives. Angewandte Chemie International Edition England 2010;49(36): 6288-6308.

[60] Mieszawska AJ, Mulder WJ, Fayad ZA, Cormode DP. Multifunctional gold nanoparticles for diagnosis and therapy of disease. Molecular Pharmaceutics 2013;10(3): 831-47.

[61] Makadia HK, Siegel SJ. Poly lactic-co-glycolic acid (PLGA) as biodegradable controlled drug delivery carrier. Polymers (Basel) 2011;3(3): 1377-1397.

[62] Elsabahy M, Wooley KL. Design of polymeric nanoparticles for biomedical delivery applications. Chemical Society Reviews 2012;41(7): 2545-2561.

[63] Nicolas J, Mura S, Brambilla D, Mackiewicz N, Couvreur P. Design, functionalisation strategies and biomedical applications of targeted biodegradable/biocompatible polymer-based nanocarriers for drug delivery. Chemical Society Reviews 2013;42(3): $1147-1235$.

[64] Yazid H, Adnan R, Hamid SA, Farrukh MA. Synthesis and characterization of gold nanoparticles supported on zinc oxide via the deposition-precipitation method. Turkish Journal of Chemistry 2010;34: 639-650.

[65] Hainfeld JF, Dilmanian FA, Slatkin DN, Smilowitz HM. Radiotherapy enhancement with gold nanoparticles. Journal of Pharmacy and Pharmacology 2008;60(8): 977-985.

[66] Cabral R, Baptista PV. The chemistry and biology of gold nanoparticle-mediated photothermal therapy: promises and challenges. Nano LIFE 2013;3(3): 1330001.

[67] Conde J, Ambrosone A, Sanz V, Hernandez Y, Marchesano V, Tian F, Child H, Berry CC, Ibarra MR, Baptista PV, Tortiglione C, de la Fuente JM. Design of Multifunctional Gold Nanoparticles for In Vitro and In Vivo Gene Silencing. ACSNANO 2012;6(9): 8316-8324.

[68] Murphy CJ, Gole AM, Hunyadi SE, Stone JW, Sisco PN, Alkilany A, Kinard BE, Hankins P. Chemical sensing and imaging with metallic nanorods. Chemical Communications 2008;5: 544-557.

[69] Huang CW, Hao YW, Nyagilo J, Dave DP, Xu LF, Sun XK. Porous Hollow Gold Nanoparticles for Cancer SERS Imaging. Journal of Nano Research 2010;10: 137-148. 
[70] Sirotkina MA, Elagin VV, Shirmanova MV, Bugrova ML, Snopova LB, Kamensky VA, Nadtochenko VA, Denisov NN, Zagaynova EV. OCT-guided laser hyperthermia with passively tumor-targeted gold nanoparticles. Journal of Biophotonics 2010;3(10-11): 718-727.

[71] Cardinal J, Klune JR, Chory E, Jeyabalan G, Kanzius JS, Nalesnik M, Geller DA. Noninvasive Radiofrequency Ablation of Cancer Targeted by Gold Nanoparticles. Surgery 2008;144(2): 125-132.

[72] Gannon CJ, Patra CR, Bhattacharya R, Mukherjee P, Curley SA. Intracellular gold nanoparticles enhance non-invasive radiofrequency thermal destruction of human gastrointestinal cancer cells. Journal of Nanobiotechnology 2008;6(2): 1-9.

[73] Bhattacharya R, Mukherjee P. Biological properties of "naked" metal nanoparticles. Advanced Drug Delivery Reviews 2008;60(11): 1289-1306.

[74] Wang J, Yao K, Wang C, Tang C, Jiang X. Synthesis and drug delivery of novel amphiphilic block copolymers containing hydrophobic dehydroabietic moiety. Journal of Materials Chemistry B 2013;1(17): 2324-2332.

[75] Lim ZZJ, Li JEJ, Ng CT, Yung LYL, Bay BH. Gold nanoparticles in cancer therapy. Acta Pharmacologica Sinica 2011;32(8): 983-990.

[76] Duncan B, Kim C, Rotello VM. Gold nanoparticle platforms as drug and biomacromolecule delivery systems. Journal of Controlled Release 2010;148(1): 122-127.

[77] Schroeder A, Heller DA, Winslow MM, Dahlman JE, Pratt GW, Langer R, Jacks T, Anderson DG. Treating metastatic cancer with nanotechnology. Nature Reviews Cancer 2012;12(1): 39-50.

[78] Hu CMJ, Aryal S, Zhang L. Nanoparticle-assisted combination therapies for effective cancer treatment. Therapeutic Delivery 2010;1(2): 323-334.

[79] Ruoslahti E, Bhatia SN, Sailor MJ. Targeting of drugs and nanoparticles to tumors. Journal of Cell Biology 2010;188(6): 759-768.

[80] Dreaden EC, Mwakwari SC, Sodji QH, Oyelere AK, El-Sayed MA. TamoxifenPoly(ethylene glycol)-Thiol Gold Nanoparticle Conjugates: Enhanced Potency and Selective Delivery for Breast Cancer Treatment. Bioconjugate Chemistry 2009;20(12): 2247-2253.

[81] Liu Y, Miyoshi H, Nakamura M. Nanomedicine for drug delivery and imaging: a promising avenue for cancer therapy and diagnosis using targeted functional nanoparticles. International Journal of Cancer 2007;120(12): 2527-2537.

[82] Xie J, Lee S, Chen X. Nanoparticle-based theranostic agents. Advanced Drug Delivery Reviews 2010;62(11): 1064-1079. 
[83] Farokhzad OC, Cheng J, Teply BA, Sherifi I, Jon S, Kantoff PW, Richie JP, Langer R. Targeted nanoparticle-aptamer bioconjugates for cancer chemotherapy in vivo. PNAS 2006;103(16): 6315-6320.

[84] Sapra P, Allen TM. Internalizing Antibodies are Necessary for Improved Therapeutic Efficacy of Antibody-targeted Liposomal Drugs. Cancer Research 2002;62(24): 7190-7194.

[85] Park JW, Kirpotin DB, Hong K, Shalaby R, Shao Y, Nielsen UB, Marks JD, Papahadjopoulos D, Benz CC. Tumor targeting using anti-her2 immunoliposomes. Journal of Controlled Release 2001;74(1-3): 95-113.

[86] Chattopadhyay N, Fonge H, Cai Z, Scollard D, Lechtman E, Done SJ, Pignol JP, Reilly RM. Role of antibody-mediated tumor targeting and route of administration in nanoparticle tumor accumulation in vivo. Molecular Pharmaceutics 2012;9(8): 2168-2179.

[87] Kao HW, Lin YY, Chen CC, Chi KH, Tien DC, Hsia CC, Lin MH, Wang HE. Evaluation of EGFR-targeted radioimmuno-gold-nanoparticles as a theranostic agent in a tumor animal model. Bioorganic \& Medicinal Chemistry Letters 2013;23(11): 3180-3185.

[88] Ang KK, Berkey BA, Tu X, Zhang HZ, Katz R, Hammond EH, Fu KK, Milas L. Impact of epidermal growth factor receptor expression on survival and pattern of relapse in patients with advanced head and neck carcinoma. Cancer Research 2002;62(24): 7350-7356.

[89] Asadishad B, Vossoughi M, Alemzadeh I. Folate-Receptor-Targeted Delivery of Doxorubicin Using Polyethylene Glycol-Functionalized Gold Nnanoparticles. Industrial \& Engineering Chemistry Research 2010;49(4): 1958-1963.

[90] Chithrani BD, Chan WC. Elucidating the mechanism of cellular uptake and removal of protein-coated gold nanoparticles of different sizes and shapes. Nano Letters 2007;7(6): 1542-1550.

[91] Kang B, Mackey MA, El-Sayed MA. Nuclear targeting of gold nanoparticles in cancer cells induces DNA damage, causing cytokinesis arrest and apoptosis. Journal of the American Chemical Society 2010;132(5): 1517-1519.

[92] de la Fuente JM, Berry CC. Tat Peptide as an Efficient Molecule To Translocate Gold Nanoparticles into the Cell Nucleus. Bioconjugate Chemistry 2005;16(5): 1176-1180.

[93] Lu W, Zhang G, Zhang R, Flores LG, 2nd, Huang Q, Gelovani JG, Li C. Tumor sitespecific silencing of NF-kappaB p65 by targeted hollow gold nanosphere-mediated photothermal transfection. Cancer Research 2010;70(8): 3177-3188.

[94] Lu W, Xiong C, Zhang G, Huang Q, Zhang R, Zhang JZ, Li C. Targeted photothermal ablation of murine melanomas with melanocyte-stimulating hormone analog-conjugated hollow gold nanospheres. Clinical Cancer Research 2009; 15(3): 876-886. 
[95] Choi CH, Alabi CA, Webster P, Davis ME. Mechanism of active targeting in solid tumors with transferrin-containing gold nanoparticles. Proceedings of the National Academy of Sciences of the United States of America 2010;107(3): 1235-1240.

[96] Melancon MP, Lu W, Yang Z, Zhang R, Cheng Z, Elliot AM, Stafford J, Olson T, Zhang JZ, Li C. In vitro and in vivo targeting of hollow gold nanoshells directed at epidermal growth factor receptor for photothermal ablation therapy. Molecular Cancer Therapeutics 2008;7(6): 1730-1739.

[97] Park C, Youn H, Kim H, Noh T, Kook YH, Oh ET, Park HJ, Kim C. Cyclodextrin-covered gold nanoparticles for targeted delivery of an anti-cancer drug. Journal of Materials Chemistry 2009;19(16): 2310-2315.

[98] Han G, You CC, Kim BJ, Turingan RS, Forbes NS, Martin CT, Rotello VM. LightRegulated Release of DNA and Its Delivery to Nuclei by Means of Photolabile Gold Nanoparticles. Angewandte Chemie International Edition England 2006;45(19): 3165-3169.

[99] Hong R, Han G, Fernández JM, Kim BJ, Forbes NS, Rotello VM. Glutathione-Mediated Delivery and Release Using Monolayer Protected Nanoparticle Carriers. Journal of the American Chemical Society 2006;128(4): 1078-1079.

[100] Mayer G, Heckel A. Biologically Active Molecules with a "Light Switch". Angewandte Chemie International Edition England 2006;45(30): 4900-4921.

[101] McCoy CP, Rooney C, Edwards CR, Jones DS, Gorman SP. Light-Triggered Molecule-Scale Drug Dosing Devices. Journal of the American Chemical Society 2007;129(31): 9572-9573.

[102] Li J, Gupta S, Li C. Research perspectives: gold nanoparticles in cancer theranostics. Quantitative Imaging in Medicine and Surgery. 2013;3(6): 284-291.

[103] Agasti SS, Chompoosor A, You C-C, Ghosh P, Kim CK, Rotello VM. Photoregulated Release of Caged Anticancer Drugs from Gold Nanoparticles. Journal of the American Chemical Society 2009;131(16): 5728-5729.

[104] You J, Zhang G, Li C. Exceptionally high payload of doxorubicin in hollow gold nanospheres for near-infrared light-triggered drug release. ACS Nano 2010;4(2): 1033-1041.

[105] Yavuz MS, Cheng Y, Chen J, Cobley CM, Zhang Q, Rycenga M, Xie J, Kim C, Song $\mathrm{KH}$, Schwartz AG, Wang LV, Xia Y. Gold nanocages covered by smart polymers for controlled release with near-infrared light. Nature Materials 2009;8: 935-939.

[106] Gu YJ, Cheng J, Man CW, Wong WT, Cheng SH. Gold-doxorubicin nanoconjugates for overcoming multidrug resistance. Nanomedicine 2012;8(2): 204-211.

[107] Brown SD, Nativo P, Smith J-A, Stirling D, Edwards PR, Venugopal B, Flint DJ, Plumb JA, Graham D, Wheate NJ. Gold Nanoparticles for the Improved Anticancer 
Drug Delivery of the Active Component of Oxaliplatin. Journal of the American Chemical Society 2010;132(13): 4678-4684.

[108] Hunt KK, Vorburguer SA. Hurdles and Hopes for Cancer Therapy. Science 2002;297(5580): 415-416.

[109] Whitehead KA, Langer R, Anderson DG. Knocking down barriers: advances in siRNA delivery. Nature Reviews Drug Discovery 2009;8(2): 129-138.

[110] Giljohann DA, Seferos DS, Prigodich AE, Patel PC, Mirkin CA. Gene regulation with polyvalent siRNA-nanoparticle conjugates. Journal of the American Chemical Society 2009;131(6): 2072-2073.

[111] Rosi NL, Giljohann DA, Thaxton CS, Lytton-Jean AK, Han MS, Mirkin CA. Oligonucleotide-modified gold nanoparticles for intracellular gene regulation. Science 2006;312(5776): 1027-1030.

[112] Han G, Martin CT, Rotello VM. Stability of Gold Nanoparticle-Bound DNA toward Biological, Physical, and Chemical Agents. Chemical Biology \& Drug Design 2006;67(1): 78-82.

[113] Han G, Chari NS, Verma A, Hong R, Martin CT, Rotello VM. Controlled Recovery of the Transcription of Nanoparticle-Bound DNA by Intracellular Concentrations of Glutathione. Bioconjugate Chem. 2005;16(6): 1356-1359.

[114] Lytton-Jean AK, Langer R, Anderson DG. Five years of siRNA delivery: spotlight on gold nanoparticles. Small 2011;7(14): 1932-1937.

[115] Gowda R, Jones NR, Banerjee S, Robertson GP. Use of Nanotechnology to Develop Multi-Drug Inhibitors for Cancer Therapy. Journal of Nanomedicine and Nanotechnology 2013;4(6): 1-16.

[116] Conde J, Tian F, Hernández Y, Bao C, Cui D, Janssen K-P, Ibarra MR, Baptista PV, Stoeger T, de la Fuente JM. In vivo tumor targeting via nanoparticle-mediated therapeutic siRNA coupled to inflammatory response in lung cancer mouse models. Biomaterials 2013;34(31): 7744-7753.

[117] Zhang W, Meng J, Ji Y, Li X, Kong H, Wu X, Xu H. Inhibiting metastasis of breast cancer cells in vitro using gold nanorod-siRNA delivery system. Nanoscale 2011;3(9): 3923-3932.

[118] Ryou SM, Park M, Kim JM, Jeon CO, Yun CH, Han SH, Kim SW, Lee Y, Kim S, Han MS, Bae J, Lee K. Inhibition of xenograft tumor growth in mice by gold nanoparticleassisted delivery of short hairpin RNAs against Mcl-1L. Journal of Biotechnology 2011;156(2): 89-94.

[119] Brooks PC, Montgomery AM, Rosenfeld M, Reisfeld RA, Hu T, Klier G, Cheresh DA. Integrin alpha $\mathrm{v}$ beta 3 antagonists promote tumor regression by inducing apoptosis of angiogenic blood vessels. Cell 1994;79(7): 1157-1164. 
[120] Wahid F, Shehzad A, Khan T, Kim YY. MicroRNAs: synthesis, mechanism, function, and recent clinical trials. Biochimica et Biophysica Acta 2010;1803(11): 1231-1243.

[121] Yu Y, Sarkar FH, Majumdar APN. Down-regulation of miR-21 Induces Differentiation of Chemoresistant Colon Cancer Cells and Enhances Susceptibility to Therapeutic egimens. Translational Oncology 2013;6(2):180-186.

[122] Baguley BC. Multiple Drug Resistance Mechanisms in Cancer. Molecular Biotechnology 2010;46(3): 308-316.

[123] Huls M, Russel FGM, Masereeuw R. The Role of ATP Binding Cassette Transporters in Tissue Defense and Organ Regeneration. The Journal of Pharmacology and Experimental Therapeutics 2009;328(1): 3-9.

[124] Wang K, Wu X, Wang J, Huang J. Cancer stem cell theory: therapeutic implications for nanomedicine. International Journal of Nanomedicine 2013;8(1): 899-908.

[125] Ganesh S, Iyer AK, Weiler J, Morrissey DV, Amiji MM. Combination of siRNA-directed Gene Silencing With Cisplatin Reverses Drug Resistance in Human Non-small Cell Lung Cancer. Molecular Therapy-Nucleic Acids 2013;2(7): 1-11.

[126] Susa M, Iyer AK, Ryu K, Choy E, Hornicek FJ, Mankin H, Milane L, Amiji MM, Duan Z. Inhibition of ABCB1 (MDR1) Expression by an siRNA Nanoparticulate Delivery System to Overcome Drug Resistance in Osteosarcoma. PLoS ONE 2010; 5(5): 1-12.

[127] Chaabane W, User SD, El-Gazzah M, Jaksik R, Sajjadi E, Rzeszowska-Wolny J, Los M. Autophagy, Apoptosis, Mitoptosis and Necrosis: Interdependence Between Those Pathways and Effects on Cancer. Archivum Immunologiae et Therapiae Experimentalis 2013;61(1): 43-58.

[128] Amaravadi RK, Thompson CB. The Roles of Therapy-Induced Autophagy and Necrosis in Cancer Treatment. Clinical Cancer Research 2007;13(24): 7271-7279.

[129] Saad M, Garbuzenko OB, Minko T. Co-delivery of siRNA and an anticancer drug for treatment of multidrug-resistant cancer. Nanomedicine 2008;3(6): 761-776.

[130] Kim D, Yu MK, Lee TS, Park JJ, Jeong YY, Jon S. Amphiphilic polymer-coated hybrid nanoparticles as CT/MRI dual contrast agents. Nanotechnology 2011;22(15): 1-7.

[131] Pan Y, Neuss S, Leifert A, Fischler M, Wen F, Simon U, Schmid G, Brandau W, Jahnen-Dechent W. Size-dependent cytotoxicity of gold nanoparticles. Small 2007;3(11): 1941-1949.

[132] Yildirimer L, Thanh NTK, Loizidou M, Seifalian AM. Toxicology and clinical potential of nanoparticles. Nano Today 2011;6(6): 585-607.

[133] Goodman CM, McCusker CD, Yilmaz T, Rotello VM. Toxicity of gold nanoparticles functionalized with cationic and anionic side chains. Bioconjugate Chemistry 2004;15(4): 897-900. 
[134] Chen YS, Hung YC, Liau I, Huang GS. Assessment of the In Vivo Toxicity of Gold Nanoparticles. Nanoscale Research Letters 2009;4(8): 858-864.

[135] Connor EE, Mwamuka J, Gole A, Murphy CJ, Wyatt MD. Gold nanoparticles are taken up by human cells but do not cause acute cytotoxicity. Small 2005;1(3): 325-327.

[136] Tsoli M, Kuhn H, Brandau W, Esche H, Schmid G. Cellular uptake and toxicity of Au55 clusters. Small 2005;1(8-9): 841-844.

[137] Ryan JA, Overton KW, Speight ME, Oldenburg CN, Loo L, Robarge W, Franzen S, Feldheim DL. Cellular uptake of gold nanoparticles passivated with BSA-SV40 large T antigen conjugates. Analytical Chemistry 2007;79(23): 9150-9159.

[138] Nativo P, Prior IA, Brust M. Uptake and intracellular fate of surface-modified gold nanoparticles. ACS Nano 2008;2(8): 1639-1644.

[139] Patra HK, Banerjee S, Chaudhuri U, Lahiri P, Dasgupta AK. Cell selective response to gold nanoparticles, Nanomedice: Nanotechnology, Biology, and Medicine 2007;3(2): 111-119.

[140] Chithrani BD, Ghazani AA, Chan WC. Determining the size and shape dependence of gold nanoparticle uptake into mammalian cells. Nano Letters 2006;6(4): 662-668.

[141] Jiang W, Kim BY, Rutka JT, Chan WC. Nanoparticle-mediated cellular response is size-dependent. Nature Nanotechnology 2008;3(3): 145-50.

[142] Arnida, Malugin A, Ghandehari H. Cellular uptake and toxicity of gold nanoparticles in prostate cancer cells: a comparative study of rods and spheres. Journal of Applied Toxicology 2010;30(3): 212-217.

[143] Hauck TS, Ghazani AA, Chan WC. Assessing the effect of surface chemistry on gold nanorod uptake, toxicity, and gene expression in mammalian cells. Small 2008;4(1): 153-159.

[144] Sabella S, Brunetti V, Vecchio G, Galeone A, Maiorano G, Cingolani R, Pompa P. Toxicity of citrate-capped AuNPs: an in vitro and in vivo assessment. Journal of Nanoparticle Research 2011;13(12): 6821-6835.

[145] Pan Y, Leifert A, Ruau D, Neuss S, Bornemann J, Schmid G, Brandau W, Simon U, Jahnen-Dechent W. Gold nanoparticles of diameter $1.4 \mathrm{~nm}$ trigger necrosis by oxidative stress and mitochondrial damage. Small 2009;5(18): 2067-2076.

[146] Li JJ, Hartono D, Ong CN, Bay BH, Yung LYL. Autophagy and oxidative stress associated with gold nanoparticles. Biomaterials 2010;31(23): 5996-6003.

[147] Li JJ, Zou L, Hartono D, Ong CN, Bay BH, Lanry Yung LY. Gold Nanoparticles Induce Oxidative Damage in Lung Fibroblasts In Vitro. Advanced Materials 2008;20(1): 138-142. 
[148] Conde J, Larguinho M, Cordeiro A, Raposo LR, Costa PM, Santos S, Diniz MS, Fernandes AR, Baptista PV. Gold-nanobeacons for gene therapy: evaluation of genotoxicity, cell toxicity and proteome profiling analysis. Nanotoxicology 2014;8(5): 521-532.

[149] Hackenberg S, Scherzed A, Kessler M, Hummel S, Technau A, Froelich K, Ginzkey C, Koehler C, Hagen R, Kleinsasser N. Silver nanoparticles: evaluation of DNA damage, toxicity and functional impairment in human mesenchymal stem cells. Toxicology Letters 2011;201(1): 27-33.

[150] Asharani PV, Xinyi N, Hande MP, Valiyaveettil S. DNA damage and p53-mediated growth arrest in human cells treated with platinum nanoparticles. Nanomedicine 2010;5(1): 51-64.

[151] El-Sayed I, Huang X, El-Sayed MA. Selective laser photo-thermal therapy of epithelial carcinoma using anti-EGFR antibody conjugated gold nanoparticles. Cancer Letters 2006;239(1): 129-135.

[152] Schaeublin NM, Braydich-Stolle LK, Schrand AM, Miller JM, Hutchison J, Schlager JJ, Hussain SM. Surface charge of gold nanoparticles mediates mechanism of toxicity. Nanoscale 2011;3(2): 410-420.

[153] Alkilany AM, Nagaria PK, Hexel CR, Shaw TJ, Murphy CJ, Wyatt MD. Cellular uptake and cytotoxicity of gold nanorods: molecular origin of cytotoxicity and surface effects. Small 2009;5(6): 701-708.

[154] Cho WS, Cho M, Jeong J, Choi M, Cho HY, Han BS, Kim SH, Kim HO, Lim YT, Chung BH, Jeong J. Acute toxicity and pharmacokinetics of $13 \mathrm{~nm}$-sized PEG-coated gold nanoparticles. Toxicology and Applied Pharmacology 2009;236(1): 16-24.

[155] Chen YS, Hung YC, Liau I, Huang GS. Assessment of the In Vivo Toxicity of Gold Nanoparticles. Nanoscale Research Letters 2009;4(8): 858-864.

[156] De Jong WH, Hagens WI, Krystek P, Burger MC, Sips AJ, Geertsma RE. Particle sizedependent organ distribution of gold nanoparticles after intravenous administration. Biomaterials 2008;29(12): 1912-1919.

[157] Sonavane G, Tomoda K, Makino K. Biodistribution of colloidal gold nanoparticles after intravenous administration: effect of particle size. Colloids and Surfaces B: Biointerfaces 2008;66(2): 274-280.

[158] Hirn S, Semmler-Behnke M, Schleh C, Wenk A, Lipka J, Schaffler M, Takenaka S, Moller W, Schmid G, Simon U, Kreyling WG. Particle size-dependent and surface charge-dependent biodistribution of gold nanoparticles after intravenous administration. European Journal of Pharmaceutics and Biopharmaceutics 2011;77(3): 407-416.

[159] Khlebtsov N, Dykman L. Biodistribution and toxicity of engineered gold nanoparticles: a review of in vitro and in vivo studies. Chemical Society Reviews 2011;40(3): 1647-1671. 
[160] Longmire M, Choyke PL, Kobayashi H. Clearance properties of nano-sized particles and molecules as imaging agents: considerations and caveats. Nanomedicine (Lond) 2008;3(5): 703-717.

[161] Harper SL, Carriere JL, Miller JM, Hutchison JE, Maddux BL, Tanguay RL. Systematic evaluation of nanomaterial toxicity: utility of standardized materials and rapid assays. ACS Nano 2011;5(6): 4688-4697.

[162] Pompa P, Vecchio G, Galeone A, Brunetti V, Sabella S, Maiorano G, Falqui A, Bertoni G, Cingolani R. In Vivo toxicity assessment of gold nanoparticles in Drosophila melanogaster. Nano Research 2011;4(4): 405-413. 